\title{
IDENTICAL TWIN GENETICS IN CATTLE
}

\author{
GERT BONNIER and ARTUR HANSSON \\ Animal Breeding Institute, Wiod, Eldtamto, Sweden
}

Received 7.vii.47

\section{INTRODUCTION}

(a) The occurrence of identical twins in cattle and their use
in research work

INTEREST in cattle twins was much aroused by the well-known studies on freemartins by Lillie $(1916,1917)$ and by Keller and Tandler (I9I6). It was then questioned whether or not monozygous twins occurred in cattle. During the early twenties the attitude towards this question was rather sceptical. Gowen (1922) made on the one hand an inquiry into the sex combinations in some small samples of twin pairs, and on the other hand a comparison of likenesses between twins of same sex, twins of different sex and non-twin sisters. $\mathrm{He}$ concluded "... it follows that identical twins (monozygotic) are rarely or never produced in cattle." Lillie, as well as Keller, believed in the occurrence of identical cattle twins, but found them to be very rare. They based their opinion on embryological data. Lillie (1923), reviewing his own and Keller and Tandler's cases, found that among I 26 known cases only one exhibited one corpus luteum for two embryos. In a later review by Keller (1933) some additional data were incorporated, and he also reported only one case with a single corpus luteum. (It is, however, impossible to find out from his account whether this is the same case as that reported by Lillie.) His conclusion is " Auf Grund dieser Befunde muss auf grosse Seltenheit eineiiger Zwillinge beim Rind geschlossen werden. . . ."

Meanwhile sporadic cases were described of equally-sexed cattle twins of such great similarity that they were judged to be identical.* Lush (1924) reported a case of bull twins found within a population of Herford $\times$ Zebu crosses. The animals were remarkably similar, which made it seem likely that they really were identical twins. In

* Kronacher (1932) mentions Hayden (1922) as the earliest paper in which a case of identical cattle twins was described, and in several later investigations this same statement has been quoted. However, in Hayden's paper, a cow is reported which gave birth to several pairs of twins among which equally, as well as non-equally, sexed pairs occurred. He does not speak of identical twins and his photographs do not support the idea that he had come across such twins. 
a later paper Lush (1929) described a pair of Jersey twin heifers, which were not only remarkably like each other, but also dropped their first calves on the same day and yielded nearly the same amounts of milk during their first 9 months of lactation. This pair was also judged by Lush as identical. Hutt (1930) describes a case in which a Holstein-Friesian cow gave birth to four living calves. Of these, one was a bull, one a freemartin and two heifers. After a thorough description of this unusual case he concludes that the two heifers were identical twins. The following quotation from his paper is of considerable interest in the present connection: "A feeding experiment repeated upon each animal and using first one twin and then the other as a control, would probably yield more conclusive results than if a dozen animals of greater genetic heterogeneity and of different ages were used for the same test." At later dates also, a number of sporadic cases of identical cattle twins have been described or mentioned (Peters, I939; Dairy Division, 1940 ; Cook, 1940 (identical triplets) and others).

The first real attempt to collect identical cattle twins for research purposes was, however, made by Kronacher (1930). He asks in this paper for support from the farmers in detecting similar-looking twins of the same sex. He estimates that about 8 identical pairs are to be expected in 100,00o births, which, in German territory at that time would mean about 500 births of identical pairs a year. Two years later Kronacher (1932) gives a comprehensive and very detailed report on 25 pairs of equally sexed twins, of which 2 pairs are described as definitely identical, 3 pairs as very probably identical, 9 pairs as possibly identical, 17 pairs as probably not identical and 4 pairs as definitely not identical.

The work of Kronacher was carried on in a number of further papers by members of his Berlin school (Sanders, I935; Kronacher and Sanders, 1936; Kronacher, 1936 ; Kronacher and Hogreve, 1936 ; Schmidt and Kliesch, 1938; Haak, 1942, 1943). This pioneer work must be given high credit in so far as it thereby became evident that identical cattle twins really were a possibility. It is also this school which pointed out some of the best characters for diagnostic purposes. Its members did, however, concentrate on questions of diagnosis to such a degree that they never went beyond them. It is true that Kronacher had already pointed out in his paper of $193^{\circ}$ as one of the most important objects of this twin research work: "Aufzucht der Eineiigen Zwillinge unter möglichst entgegengesetzten Verhältnissen, um schliesslich entscheiden zu können, was erblich bedingt und was Modifikation ist !" But he also pointed out that such investigations could not be begun until reliable methods of diagnosis had been evolved. This was of course true. But the same objection against undertaking planned experiments has been repeated over and over again by the different members of the school. And, as a matter of fact, they have never carried out anything which could 
be called a planned experiment. From the point of view of contributions to our knowledge of the genetics of production ability, and of how different genotypes respond to differences in environment, the Kronacher school has thus yielded very little.

In the latest paper from this school, Haak (1943) publishes measurements from all twin pairs investigated since the start of the work. Apart from a great number of fraternal twins, his material contains 19 pairs of identical twins. This figure is surprisingly low for a period of about Io years when compared with the estimate of 500 births of identical pairs a year in Germany made by Kronacher (1930), especially as this latter estimate is probably too low (cf. Bonnier, I $946 a$ ). It is also noteworthy that Haak could not include 6 pairs in his material because they were too young, and therefore impossible to diagnose. According to our experience it is very important to diagnose twin calves-at least preliminarily-when they are only a few weeks old, since otherwise the experiments cannot be started early enough.

However, as soon as it became evident that identical cattle twins really do occur, it was a very natural step to try and collect such twins for well-planned experiments. The senior author of the present article, who, during the early thirties, was occupied with some cattle breeding studies, was troubled by our profound lack of knowledge as to how much information a cow's yield gives with regard to her hereditary qualities. It was especially the question of the influence of feeding intensity which was at stake: Was a high yielding cow from a herd with high feeding intensity necessarily genetically better than a low yielding cow from a herd with a lower feeding level? For practical breeding work it is obviously of the utmost importance to obtain some kind of answer to questions of that sort. Experiments were therefore undertaken in which consumption as well as production of a number of cows was closely checked. In this connection groups of cows were, for shorter or longer periods, given amounts of feed which were higher than those corresponding to their actual yield (Bonnier, I 930, 1931, 1932, Bonnier and Bäckström, 1935). The results indicated that the genotype of the cow determines a ceiling, above which her yield could not be forced by an increase in feeding intensity. It was, however, clear that the problems had many aspects, and that, in order to attack them adequately, a better planning of the experiments was necessary. Consequently, Kronacher's paper of 1932 being then available, the idea of starting feeding experiments with identical cattle twins came readily to mind. The first plans were made during 1936, and the first experiments begun during the spring of 1937 (cf. "List").

Since the experimental twin work was inaugurated at Wiad, work of a similar kind has been started in different parts of the world. The most extensive is definitely that at Ruakura Research Station near Hamilton, New Zealand, where there are not less than 55 pairs 
of identical twins (New Zealand Dairy Board, 1946). Twin experiments are also planned or already under way in Norway, Denmark and Finland. In the Veterinary Institute at Skara, in the west part of Sweden, work with identical cattle twins has been taken up for the purpose of studying some deficiency diseases.

As stated above, Lillie (1923) found only one case of twin fotuses with one corpus luteum among 126 cases of equally sexed twin foetuses. In contradistinction to this, our estimate (Bonnier, I946a) is about 8 identical pairs among Ioo equally sexed twin pairs. This is rather too large a discrepancy, and an explanation must be sought. Tentatively two explanations might be given : (I) It does not seem impossible that an old corpus luteum may be revived, so that in certain cases a monozygous pair may be accompanied by two corpora lutea. (2) Lillie himself (1923) calls attention to the fact that the butchers, on whom he relied for selecting uteri containing twins, would be likely to overlook twin pregnancies confined to one horn of the uterus. Now, it is to be supposed that identical twins always, or nearly always, lie in the same horn. Consequently these twin pairs will be present in proportionately smaller numbers in such collections of pregnant uteri, than in twin births.

In conclusion it is worth noting that Gowen based his opinion that identical twins were rare in cattle on three different samples containing, when pooled, 7I pairs of two males, 209 pairs of one male and one female, and 107 pairs of two females, thus there were in all 387 pairs. Now, it has been shown (Bonnier, 1946a) that the maximum likelihood estimate of the proportion of identical twins among all pairs of equally sexed twins, $m$, is

$$
m=\frac{2 n p q-n_{2}}{2 p q\left(n-n_{2}\right)}
$$

where $n$ is the total number of pairs, $n_{2}$ the number of pairs containing one male and one female, $p$ the sex ratio (proportion of males) and $q=\mathrm{I}-p$. The standard deviation of $m$ is calculated to be

$$
2(\mathrm{I}-2 m p q) \sqrt{\frac{\mathrm{I}-m}{n}} \text {. }
$$

Using this formula for $m$, a material containing 4655 twin pairs gave as estimate of $m, 0.0848$ (Bonnier, 1946a). The question is therefore: How do Gowen's data fit this estimate? Taking $n, p$ and $q$ from Gowen's figures, i.e. taking $n=387, p=0.4535$ and $q=0.5465$ but using the above value of $m=0.0848$ and substituting in the formula for the standard deviation of $m$, this is found to be 0.0932 . Consequently, if 0.0848 is the "true" estimate of $m$ in a population where $p=0.4535$, a sample of 387 pairs in which $m$ is found to be zero is conceivable. There is thus no contradiction on 
this point of view between Gowen's data and those reported elsewhere (Bonnier, 1946a). It may, however, be recalled that Gowen's sexratio $p=0.4535$ is unusually low.

\section{(b) The diagnosis of identical twins}

The tests of monozygosity were based on morphological comparisons as well as on serological tests ( $c f$. Bonnier and Hansson, 1946). We hoped-and believed - that these serological tests would prove to be of a crucial nature. Since then, however, American investigations have shown (Owen, 1945) that there are no blood reactions after transfusions either between identicals or, in the majority of cases, between fraternals. This is due to the common blood vessel which is known to link the twins during the fotal life in about 90 per cent. of all cattle twin pregnancies. All tests of the young calves must therefore be based on morphological grounds. The following criteria seemed to us to be of value ( $c f$. Bonnier and Hansson, 1946) :-

Markings and shade of colour.

Number, position and direction of hair-whorls.

Size, position and colours of eyes.

Colour and shape of tails and especially of tail brushes.

Colour and print of muzzles.

Shape of udders, ears and heads.

The way in which the hairs cover different parts of the body.

There is unfortunately no single character which is crucial ; and conversely, any one character might be dissimilar on the two twins without affecting their monozygosity. For instance, markings and colour distributions, though of the same general type, may be rather dissimilar in their outlines, as may easily be seen on available cases of Siamese cattle twins. In a case with two heads, four fore legs, two hind legs and two tails the expression of the colour markings on the two fore heads and the four fore legs are seen in the plate. It is obvious that the contour lines of the markings are rather dissimilar. The fore legs show mirror imaging; in fact, mirror images are met with rather commonly.

It happens now and then that some special, more or less uncommon character, is found in one of the twins. If the same character is not found in the other twin, we are very much inclined to discard the pair as being fraternal. As examples of such not too common characters the following two may be mentioned: extra teats (one or two, including their positions); asymmetrically situated hair-whorls in the face.

It is difficult to order the different characters with regard to their importance for diagnosis. We think, however, that for instance, colour-shade of the body and colour and shape of tail brushes always 
must be strongly similar in two identical twins, whereas this is less necessary with regard, for instance, to shape of markings. Now, it is of course in itself difficult to grade the degree of resemblance for characters which cannot be exactly measured. And we think it inadvisable to use some formula including grading-figures for tests of monozygosity, since this seems to us to give an air of more exactitude to the tests than they in fact have.

But there is another body of facts which seems to us to add much to the exactitude of our final diagnoses. As pointed out above, we make the first tests as soon as the twin calves arrive at the Institute, i.e. when the calves are only a few weeks old. Several pairs are already at that moment discarded as being more or less surely fraternals or at least so much dissimilar that they never could be proved to be
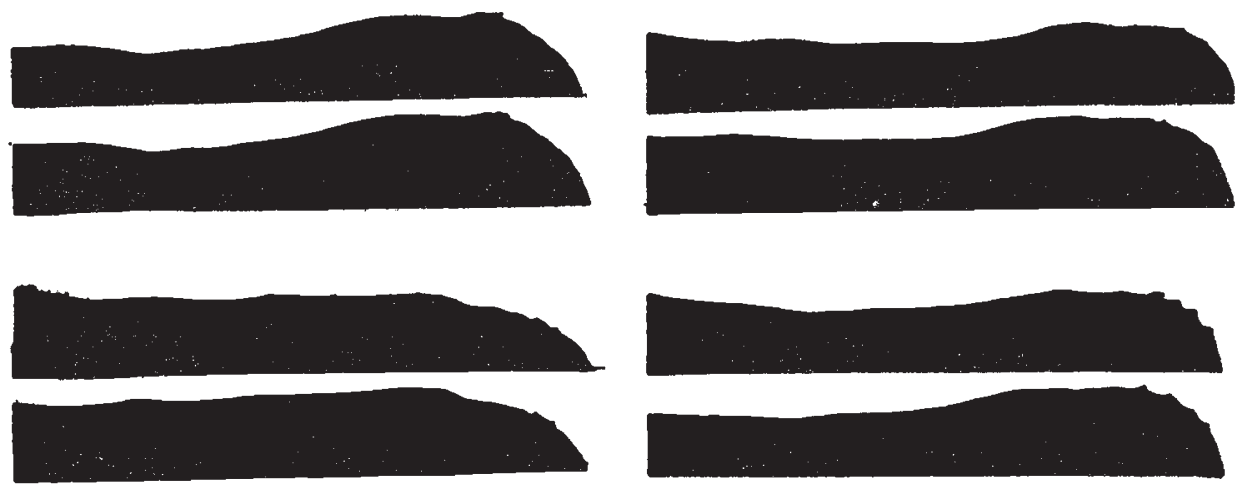

FIG. 1.-Photographs of contour lines of the backs of four grown-up identical twin pairs.

identicals. Of the pairs which are retained as identicals, some are similar to such a high degree as to make a very quick diagnosis possible, whereas in others the first diagnoses take longer time. But in any case, these first diagnoses are made on very young animals, and this means that fewer characters are available for diagnosis than if the tests had been made later: the young calves have no horns, no full-grown udders, no clear silhouette lines under the jaws or of the backs. And there are several other characters which are lacking for comparisons of young animals. But if the primary test, according to which a certain pair has been classified as identical, was correct, then of course all later full-grown characters must also be similar to a high degree. It has accordingly happened in a few cases that we have had to discard twins which we earlier had believed to be identical. In the great majority, however, all later developing characters have proved to be as similar as those on which the first tests were based (fig. I). 


\section{(c) The efficiency of experiments with identical twins}

There are obviously many reasons which account for the fact that Applied Genetics has made so much more progress in the field of agricultural plants than in that of farm animals. For instance, several of the most important plants (e.g. wheat) are autogamous, and thus, after crossing attain homozygosity, i.e. constancy, in a few generations and without interference from an experimenter. Such constancy, so important from the practical breeder's point of view, is already reached at the beginning in all those plants which normally reproduce vegetatively (e.g. potatoes) or apomictically (e.g. many pasture grasses). Further, in allogamous species, the very high numbers of individuals result in the fact that only small variations occur from generation to generation in the proportions of the different genotypes, and thus, in this case as well, quite a high degree of constancy is secured. It may also be recalled that yield, the genetics of which is studied, is often sex-limited in animals (e.g. milk, eggs), which renders all investigations more difficult. The usually slower rate of change of generation, the smaller numbers in the progenies of the parental pairs, and the much higher costs of the individuals are finally also worthy of mention.

But there is still one important fact, which renders the application of genetic principles and the interpretation of experimental results more difficult in the case of animals than of plants : namely, that the plant breeder has much greater possibilities of arranging his experiments in such a way as to make the results appropriate for a penetrating statistical analysis. To divide the variance according to different causes of variation, and hence to eliminate the influence of certain causes, when studying the effect of other causes, has been made possible by investigation into the design of plant experiments, as studied, e.g. by Fisher (19.35). One has, for instance, only to recall the randomisation of blocks and the Latin Square method, by which influences of soil differences can be effectively eliminated, and consequently true estimates be made of the effects of differences of variety and manure, as well as of non-linear interactions between these two causes.

No corresponding method applicable to animal investigations has hitherto existed. There are two different types of method which are usually made use of within this sphere of study. The first of these is the statistical treatment of data collected from the field as introduced by Wright (1920, I921 $a, 192 \mathrm{I} b$ ) and fulfilled in such a remarkable way by Lush and his school. (Amongst their many papers, the following may be quoted : I935, I936, I940, I942). Much knowledge of great importance has indeed been gained by this method. But as being based on field-collected figures the raw material of these studies will never have the merit of figures gained from well-controlled experiments, and cannot be made accessible for detailed statistical 
treatment in the same way as can experiments which are especially designed with this purpose in mind. The other method is an experimental one which, however, has never-or at least very seldombeen used for studies of genetical differences, but much more for studies of differences between feeding stuffs, managements and so forth. This method consists of dividing the animals into a number of groups and treating the groups in different ways. But the differences between the average yields of the groups are due not only to differences of treatment, but also to genetical differences. In order to minimise these latter differences-which will be included among the variance due to error-two means are available :

(I) All groups should contain the same number of animals, and, to each animal in one of the groups, there should correspond one animal in each of the other groups. With the aid of what knowledge there may be at hand, this correspondence is made in such a way that the performance of all animals within a set of corresponding animals is as equal as possible at the beginning of the experiment. For instance, when a group experiment is started in cattle with the aim of studying the influence of some special feeding stuff on milk production, all cows within a set of corresponding cows should yield the same daily amount when the experiment starts. But if this equality at the start is to be of any value, it must implicitly be supposed that the animals would remain equal if all groups had been treated similarly. It is, however, a simple task to show by examples (Bonnier, Hansson and Düring, 1946) that this similarity in milk production is extinguished very quickly. In contradistinction to this, if the experiment contains two groups, and if, to each cow in one of the groups there corresponds an identical twin sister in the other group, the equality of the two groups is absolute and ascertained at the end as well as at the beginning of the experiment.

(2) The groups are made as large as possible. But, especially in the case of such expensive animals as cattle, it is difficult to maintain experiments in large groups except for rather short periods. Therefore a group experiment is usually completed within the space of a few months, and often after a few weeks. However, it is our experience that many conclusions which would have been drawn from an experiment on cattle yield would have been quite erroneous if the experiment had been ended after such a short time.

It is now possible to study how large two groups of cattle must be in the case where the cows of the one group are mainly unrelated to the cows of the other group, in order to make the experiment as efficient as if each group had contained one twin of a number of identical twin pairs. Two experiments may, in this connection, be said to be equally efficient if they give the same amount of information, i.e. if their significance is equal. Such a study is made by comparing, on the one hand, the mean squares between twin pair means, with, on the other hand, the mean squares within pairs. In the case where 
all animals are treated similarly, the ratio of these two mean squares measures the relative efficiency of the two kinds of experiments. As has been shown (Bonnier, Hansson and Düring, r946), twin experiments are at least twenty times as efficient as ordinary group experiments in the case of experiments on growth rates of young heifers. In the case of milk yield, no appropriate experiments are available for such comparisons, but it has seemed fair to conclude that the twin experiments in such a study are at least five times as efficient as group experiments. Thus these conclusions, for instance, tell us that in a study on growth three pairs of identical twins give at least the same amount of information as if the experiment had been performed as an ordinary group experiment with two groups each containing sixty animals. Twin experiments can therefore, without affecting their efficiency, be made with very much smaller numbers of animals. It must, though, be remembered that twin groups which are too small may affect the animals' representativeness of their breed.

Identical cattle twins are a very suitable means for studies of many different kinds, and the high efficiency of twin experiments guarantees not only more significant results, but also smaller experimental costs. They are especially suitable for all kinds of investigations on the effects of different environments upon yield, growth, disease, fertility and so forth. And, in the cases where the experiments are well designed, a very good knowledge will also be gained with regard to the rôle played by heredity, as well as with regard to the importance of non-linear interactions between heredity and environment. It is obvious that the experimental plans may be varied in a practically unlimited number of ways. But it is also obvious that the more the plans are varied, the deeper and fuller will our knowledge be about the forces in action. It seems, therefore, to be highly desirable that experiments with identical cattle twins should be undertaken in many experimental investigations.

\section{THE DESIGN OF TWIN EXPERIMENTS}

A series of experiments in which $n$ pairs of identical twins are involved may be outlined as a $2 \times n$ table (table I). The letters in the table may denote either the animals themselves or the character to be studied, such as milk yield, body weight, fertility, length of hair, grade of resistance to some disease, metabolism of a particular substance, heart activity, and so forth. Now, in a table containing $n$ rows and two columns the variance can be separated into three parts, viz. that due to differences between rows, that due to differences between columns and that due to non-linear interactions between rows and columns. In a twin experiment the different pairs come, in the great majority of cases, from different herds, and the pairs are consequently practically always unrelated. The differences between rows are thus due to hereditary causes, though only mainly, since 
environment also has some influence as long as all $A$-animals are not treated exactly alike, and as long as the same is not the case with all $a$-animals. On the other hand, the differences between columns

TABLE I

Diagram to illustrate a twin experiment

\begin{tabular}{|c|c|c|c|}
\hline \multirow{4}{*}{} & \multicolumn{2}{|c|}{ Twins } & Total \\
\cline { 2 - 4 } & $A_{1}$ & $a_{1}$ & $\begin{array}{l}A_{1}+a_{1} \\
A_{2}\end{array}$ \\
$\dddot{A}_{n}$ & $a_{2}$ & $\dddot{a}_{2}$ \\
\hline Total & $\dddot{A}_{n}+a_{n}$ \\
\hline & $A_{1}+A_{2}+\ldots+A_{n}$ & $a_{1}+a_{2}+\ldots+a_{n}$ & $\begin{array}{c}A_{1}+A_{2}+\ldots+A_{n}+ \\
+a_{1}+a_{2}+\ldots+a_{n}\end{array}$ \\
\hline
\end{tabular}

are entirely of an environmental nature, since there are no genetical differences between two identical twins. Thus one of the grounds for classification is wholly due to one particular cause, whereas the other is due to another cause but only in addition to the foregoing one. If, therefore, it is desired to make a partition of the variance according to heredity, environment and non-linear interactions between heredity and environment - and this is in many of our experiments an important problem - then one must in the design of the experiments, endeavour to make the environmental differences between rows, i.e. between twin pairs, as small as possible. The ideal would be to treat all $A$-animals exactly alike and to do the same with all $a$-animals. We will refer to this principle under the name of "equality principle." Now, feeding intensity interferes with practically all functions which may be the subject of cattle studies, and our investigations are therefore primarily devoted to studies of the effects of different feeding intensities. With regard to the design of experiments, this means that the equality principle should especially be applied to feeding, i.e. we must try to feed all $A$-animals as equally as possible and also all $a$-animals as equally as possible. But when doing so the serious difficulty arises : What is to be meant by " equal feeding"?

In ordinary practice the animals are fed with regard to their own weights and yields. Thus if one heifer weighs more than another heifer, the former gets more fodder to eat, even if the animals are of the same age. Likewise, a cow which has a higher daily milk yield than another is also given higher rations. The reason for this practice is self-evident, and, though two animals of different growth rates or different milk yields get different amounts of feed, this practice ensures, as far as possible, an equal state of nourishment. And from this point of view it may be said that feeding according to weight and milk yield fulfils the requirements of the equality principle. On the other hand, it may reasonably be claimed that the equality 
principle is better fulfilled if the animals are really given equal amounts of feed. (To measure if two amounts of feed are in reality "equal" is, however, a very difficult task. No reliable method exists. In our 'experiments we use the ordinary Scandinavian method of expressing the amounts in "Scandinavian feed-units"one Scandinavian feed-unit containing 1660 net calories-and in grams of digestible protein). Since, according to this interpretation of the equality principle, no regard is paid to individual performances when making up the individual feed-schedules, these feed-schedules may be worked out in advance. But in doing this there are still details in the planning of the experiment which must be settled. During growth the most natural basis for this plan is the average growth curve within the breed. To each age there corresponds a certain weight, and to this weight there again corresponds a certain amount of feed. Thus a curve may be calculated, in which the abscissa is age and the ordinate is amount of feed appropriate for a normal growing heifer of the breed in question. Thereafter all animals in the experiment may be fed according to this "normal" curve, or two parallel curves may be drawn at different levels-for instance one above and one below the " normal "- -and the $A$-animals fed according to the upper and the $a$-animals according to the lower curve. During the first lactation a corresponding plan may be formulated. The basis is here a curve in which the abscissa is time instead of age, the origo being at the date of calving. The ordinate is amount of feed appropriate for a first-lactation cow of average growth, weight and milk yield. As before, all cows in the experiment may be fed according to this " normal" curve, or two parallel curves may be drawn-for instance one above and one below the "normal "-and the $A$-animals fed according to the upper, and the $a$-animals according to the lower curve. Corresponding feed-schedules may be worked out for later lactations.

The two interpretations of the equality principle will here be referred to as interpretation I-feeding according to individual weight and yield-and interpretation 2-feeding related to "normal" feeding curves.

One objection to the plan according to interpretation 2 is that its logical sequence may be said to be broken just at calving. If all $A$ animals are to be fed equal amounts, and also all $a$-animals are to be fed equal amounts, these two amounts ought to, one may say, refer to ages, i.e. the total amount of feed consumed from the beginning of the experiment (the start of which in our experiments is practically never later than at an age of 30 days) and up to any given age ought to be the same for all $A$-animals and also the same for all $a$-animals. But it is impossible to arrange matters so that several animals calve at exactly the same age. If, for instance, animal $A_{1}$ calves at an age of 900 days and animal $A_{2}$ at an age of 930 days, $A_{2}$ has, prior to calving, consumed 30 days more feed than $A_{1}$. The logical demand would 
thus seem to be that the "normal" feeding curve should comprise en suite youth and mature age and be made up with regard to the " normal " individual's growth rate, milk yield, and date of calving. The individual feeding within the experiment should thereafter be made regardless not only of the individual's own weight and yield, but also regardless of her age at calving. But this has seemed to us to be too great a violation of nature, and to carry a logical consequence ad absurdum.

As pointed out above, our principal studies are devoted to questions concerning feeding intensities, i.e. concerning the effect of quantitative variations. This does not, of course, mean that questions regarding the effect of qualitative variations in the fodder are unimportant, but that with regard to the relatively limited number of identical twin pairs available, the two types of questions may be treated separately. And, in order to maximise the possibilities of a correct interpretation of the results, one should try and avoid qualitative differences in the feed when studying the effects of quantitative variations. To give the two sisters of each twin pair a fodder of equal qualitative composition is as a rule easily performed. (In our earlier experiments we did not adhere to this principle, but we have done so in all later experiments.) But to give all $A$-animals or all $a$-animals a qualitatively equal fodder is more difficult, since different twin pairs usually pass given ages at different seasons of the year, and since the fodder available at different seasons is usually qualitatively different. To avoid this difficulty all twin pairs taking part in the same experiment ought to be as near the same age as possible. (Hitherto we have collected our twins during different seasons, but we are now trying to confine the collection to a few spring months.)

Apart from a number of smaller series, the experiments with identical cattle twins (females) on effects of variations in the feeding intensity, which are conducted at the Animal Breeding Institute, are distributed in the following series :-

(I) Prior to first calving, feeding according to equality principle, interpretation 2 ( $A$-animals about 33 per cent. above and $a$-animals about 33 per cent. below " normal"). From first calving all animals normally fed and according to interpretation I. (Experiment IV in "List.") In this experiment no regard was paid to the desirability of avoiding qualitative differences between the feed of $A$ - and $a$-animals.

(2) Prior to first calving, feeding according to equality principle, interpretation $2(A$-animals about 25 per cent. above and $a$-animals about 25 per cent. below "normal"). From calving according to interpretation 2 ( $A$-animals about 12.5 per cent. above and $a$-animals about I 2.5 per cent. below " normal "). (Experiment VI in "List.")

(3) Prior to first calving, all animals ( $A$ and $a$ ) normally fed and according to equality principle, interpretation I. From first calving according to interpretation 2 ( $A$-animals about 12.5 per cent. above 
and $a$-animals about 12.5 per cent. below " normal "). (Experiment VIII in " List.")

(4) Prior to first calving all animals ( $A$ and $a$ ) normally fed and according to equality principle, interpretation I. From first calving, that animal which calves first in each pair is reckoned as an $A$-animal, and the $A$-animals are fed normally and according to interpretation I after first calving. Each separate $a$-animal is then fed in relation to her $A$-sister. Hitherto no pairs have calved, but it is planned to start series in some of which the $a$-animals are fed below their sisters (for instance 80 per cent.), and in some of which they are fed above their sister (for instance, 120 and 140 per cent.). (Experiment IX in "List.")

(5) Prior to first calving one of the twin-sisters is reckoned as an $A$-animal, and all $A$-animals are fed normally and according to equality principle, interpretation I. Each separate $a$-animal is then fed in relation to her $A$-sister (6o, 80, I 20, I40 per cent. of the sister's feed amount). The plans of feeding after first calving are not yet worked out.

(All definitions above refer to the experimental plans. In the actual carrying out of the experiments some minor deviations have been impossible to avoid.)

\section{THE "CEILING" CONCEPT}

Our work with identical twin cattle is typical long-term work. Though it has now been going on for a decade it has as yet not passed its initial stages. Still, some results concerning the principles of how heredity and environment co-operate would appear to have crystallised out. That this co-operation is a very complex one is what is to be expected. But, in the case of the relations between feeding intensity and quantitative characters, it seems nevertheless possible to make some statements in terms which are simple enough, so long as they are not entered into in too much detail.

All the experiments which have hitherto been performed at Wiad with identical twins indicate very strongly that there exists a genetically determined "ceiling" with respect to all kinds of quantitative characters. The word "ceiling" means that at each moment of a cow's life there is a production maximum above which she cannot rise, irrespective of the amount of feed consumed. Stated in such a general way, the ceiling concept may, however, be looked upon as a truism : a milk yield of, say, roo kilogrammes per day is evidently a ceiling which no animal reaches. But we find that there must exist ceilings at different levels which are characteristic of different genotypes.

The following examples may help to illustrate the matter. During the growth period there are, of course, considerable differences in the 
growth rates of the $A$ - and $a$-animals of each pair in our experiments IV and VI ( 1 and 2 in the description, p. I2) and especially so when this rate is measured as an increase in live weight (Bonnier and Hansson, 1946 ; Bonnier, $1946 b$ and unpublished). Still, there are also marked differences between different pairs, which includes big differences between $A$-animals. There is strong reason to believe that these $A$-animals have been given so much feed that they have been able to make use of their whole growing capacity. But in spite of this, and in spite of the fact that all $A$-animals have consumed equal amounts of feed, their increase in weight from 30 to 8 ro days of age varies in experiment VI (table 2) from $3^{82}$ to $4^{82}$ kilogrammes.

TABLE 2

Increase in live weights and heights of shoulders from $I$ to 27 months of age of 8 twin pairs taking part in experiment VI (experiment 2 in description, p. 12)

\begin{tabular}{|c|c|c|c|c|}
\hline & \multicolumn{2}{|c|}{$\begin{array}{c}\text { Increase in live weights } \\
\text { (kilogrammes) }\end{array}$} & \multicolumn{2}{|c|}{$\begin{array}{c}\text { Increase in height of shoulders } \\
\text { (centimetres) }\end{array}$} \\
\cline { 2 - 5 } & $A$ & $a$ & $A$ & $a$ \\
\hline & & & & \\
$322-323$ & 398 & 324 & 50 & 49 \\
$327-328$ & 456 & 347 & 43 & $4 \mathrm{I}$ \\
$403-404$ & 382 & 316 & 49 & 45 \\
$409-410$ & 438 & $34 \mathrm{I}$ & 47 & 47 \\
$4 \mathrm{II}-112$ & 438 & 366 & 54 & 54 \\
$413-414$ & 482 & 364 & 53 & 55 \\
$419-420$ & 444 & 375 & 53 & 55 \\
$427-428$ & 468 & 396 & 52 & 51 \\
\hline
\end{tabular}

It is, for instance, hardly conceivable that any rise in food consumption would have been followed by an increase in weight of the $A$-animal in pair 403-404 during the period in question so that it would have

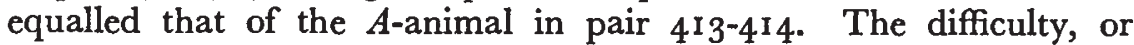
impossibility, of raising a growth rate above a certain level, the " ceiling," by more intense feeding, is still more pronounced with regard to the body measurements, such as height of shoulders (table 2).

In fig. 2 growth curves are shown for two pairs taking part in experiment VI (experiment 2, description, p. 12) ; fig. $2 a$ shows the growth of live weight and fig. $2 b$ the growth of height of shoulders; 323 and 328 are $A$-animals and 322 and $327 a$-animals. The two $A$-animals have consumed the same amount of feed (measured in feed units) and the two $a$-animals have also consumed equal amounts. The amount of the $a$-animals was 60 per cent. of that of the $A$-animals. In spite of these circumstances the heredity of the pairs $322-323$ and 327-328 determined the first of these pairs to be slow growing and the other pair to be fast growing. The two figs. $3^{b}$ and $3^{c}$ show that in the 


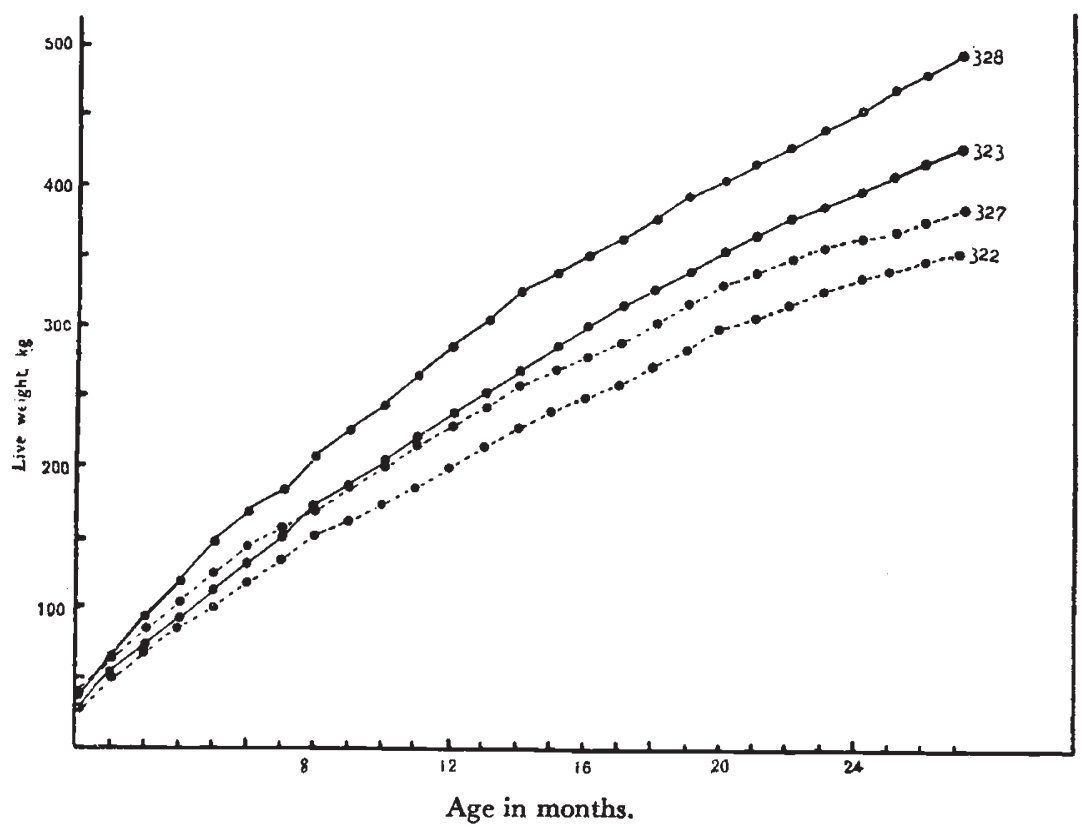

Fro. $2 a$.

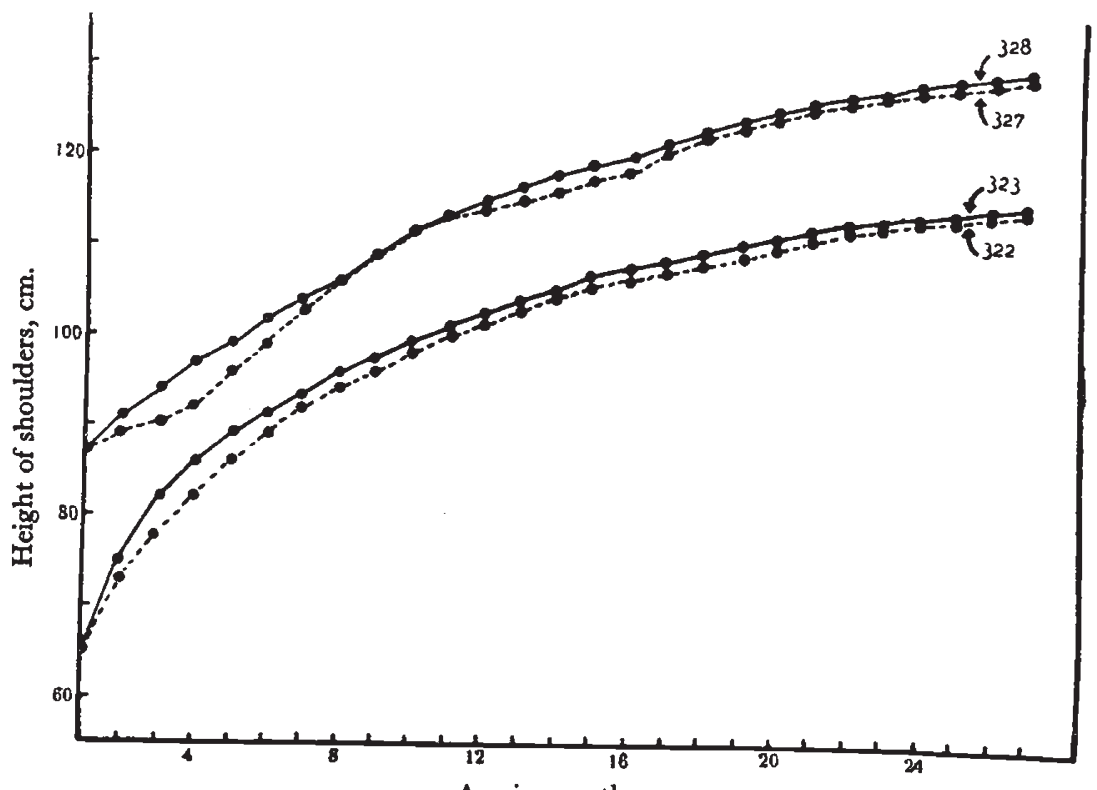

Age in months.

FIG. $2 b$.

FrG. 2.-Growth curves of two twin pairs taking part in experiment VI (exp. 2 in description, p. 12) : (a) growth of live weight; (b) growth of height of shoulders. The animals 322 and 323 form one pair and the animals 327 and 328 another pair. 323 and 328 are $A$-animals, fed 25 per cent. above an average normal heifer of the Swedish Red and White breed; $3^{22}$ and 327 are $a$-animals, fed 25 per cent. below the same average. 
case of height of shoulders the heredity plays a much more important rôle than in the case of live weight.

Figs. 3 show average curves of $A$-animals and $a$-animals taking part in experiment IV (experiment $I$ in description, p. I2) and in experiment VI (experiment 2 in description, p. I2). The curves corresponding to experiment IV are averages for 9 pairs and the curves corresponding to experiment VI are averages for 8 pairs. The $a$-animals in experiment IV have consumed $5^{\circ}$ per cent. of their

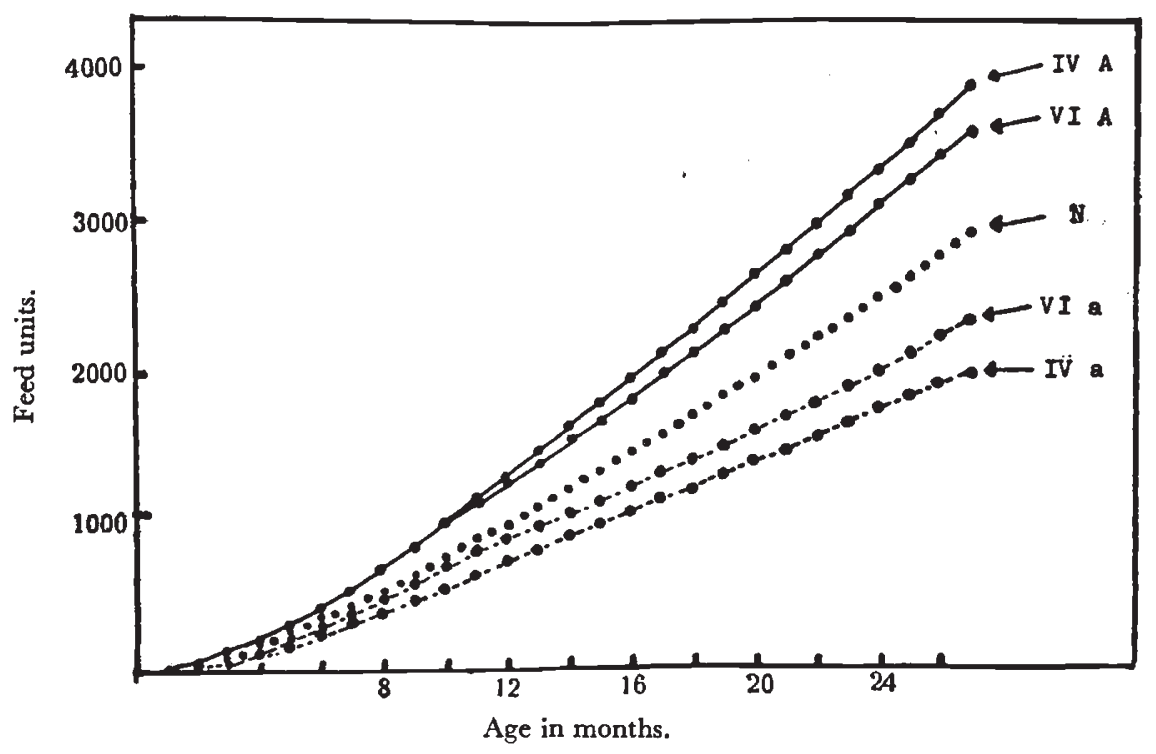

Fig. $3 a$.

Fig. 3.-Average feed and growth curves of 9 twin pairs taking part in experiment IV (exp. I in description, p. 12) and of 8 pairs taking part in experiment VI (exp. 2 in description, p. 12) ; (a) total amount of feed units given to each $A$-and to each $a$-animal of the two experiments, as well as the amount of feed units corresponding to a normal growing average heifer of the Swedish Red and White breed (N). The total amount of feed units given to $A$ - and $a$-animals lies in experiment IV 33 per cent. above and below the normal (N), and in experiment VI 25 per cent. above and below the normal (N) ; (b) average growth of live weights of $A$ - and $a$-animals of the two experiments, as well as growth rate of a normal growing average heifer of the Swedish Red and White breed $(\mathrm{N})$; (c) average growth of height of shoulders of the $A$ - and $a$-animals of the two experiments.

twin sisters, whereas the corresponding figure for experiment VI is 60 per cent. The consumption is shown in fig. $3 a$. $\mathrm{N}$ designates average of the breed. In accordance with the feeding plan the curves in this fig. are symmetrically distributed on either side of the curve $\mathrm{N}$. Fig. $3^{b}$ shows the average growth curves as measured by live weight. It is evident that the curves in this case are unsymmetrically distributed : the distance between the two $a$-curves is much greater than between the two $A$-curves, and the curve $\mathrm{N}$ runs closer to the $A$-curves 
than to the $a$-curves. And in fact, the animals VI $A$ have averagely grown faster than the animals IV $A$, though they have got less to eat. At any rate, fig. $3^{b}$ makes it very probable that the ceiling is

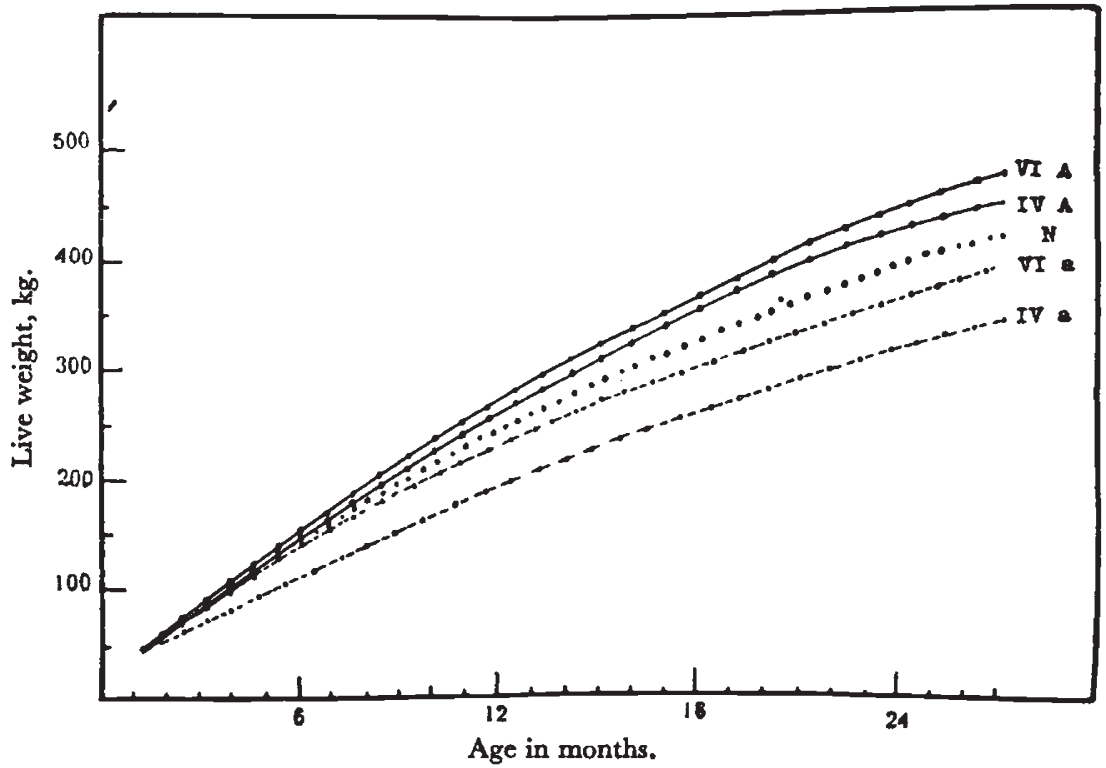

Fro. $3^{b}$.

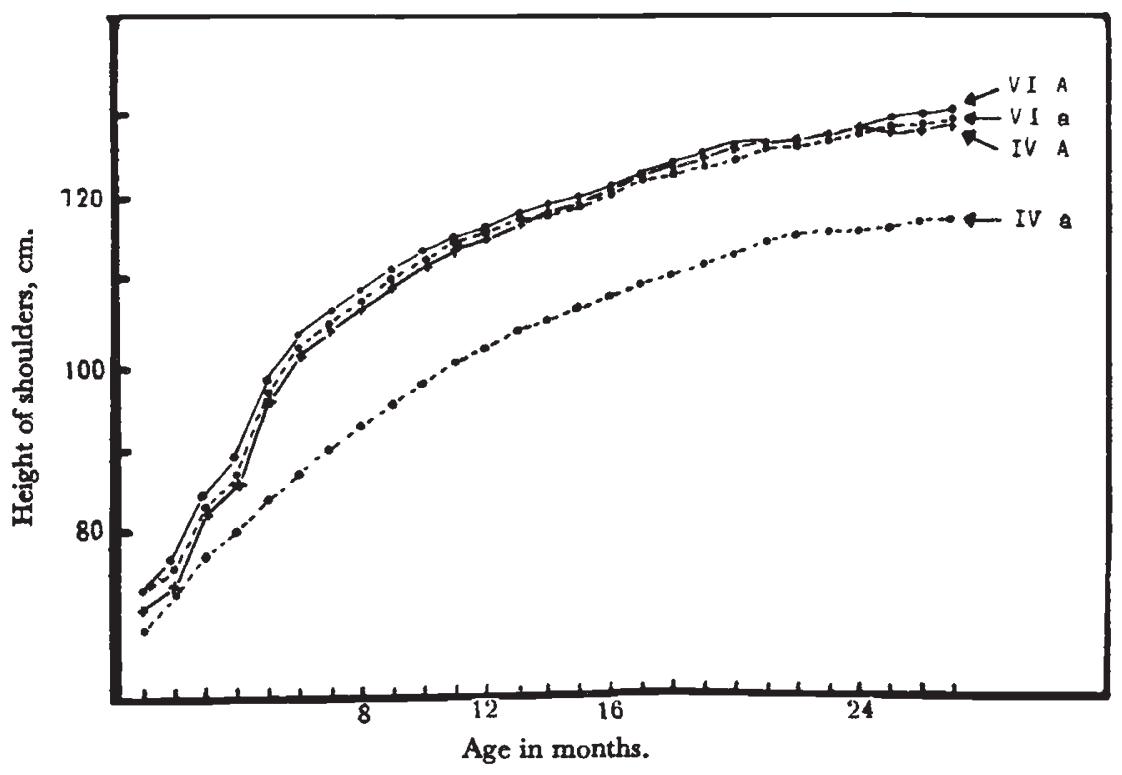

Fig. $3 c$.

Legend on opposite page.

reached in VI $A$ as well as in IV $A$. Fig. $3 c$ finally shows the corresponding average curves of height of shoulders. It is seen that the three curves IV $A$, VI $A$ and VI $a$ run on the same level, whereas 
the curve IV $a$ runs very much lower. The feeding in IV was 33 per cent. above and below normal and in VI 25 per cent. above and below normal. Fig. $3^{c}$ may thus be explained by saying that a feeding of 25 per cent. below normal interferes very insignificantly with the animals' possibilities to reach their ceilings of height of shoulders. By increasing this feed shortage from 25 to 33 per cent. a critical limit must, however, have been passed as the severe effect shown in curve IV $a$ has been the result. ( $C f$. section 4 of this paper with remark on a gradient.)

That similar kinds of conclusions must be drawn concerning milk yield has been shown in the case of experiment IV in an earlier preliminary paper (Bonnier, 1946b). In the case of experiment VI, in which equality rule, interpretation 2, also prevails after calving, some figures may be given here. Five pairs from this experiment have, up to date, been milked during 36 weeks of their first lactation. In this case, from the day of calving and onwards, all $A$-animals have received 12.5 per cent. more and all $a$-animals 12.5 per cent. less than a "normal" first lactation cow should get. "Normal" cow means here a cow which, during the first 36 weeks after calving, produces 3r95 kilogrammes of fat-corrected milk (F.C.M.), and which weighs 440 kilogrammes at calving, and increases this weight during the 36 weeks to 455 kilogrammes. Table 3 shows the actual

TABLE 3

Production of 5 twin pairs taking part in experiment VI

(experiment 2 in description, p. 12)

\begin{tabular}{|c|c|c|c|c|c|c|}
\hline \multirow[t]{2}{*}{ Pair nr. } & \multicolumn{2}{|c|}{$\begin{array}{l}\text { Fat corrected milk, } \\
\text { kilogrammes, during } \\
\text { first lactation's } 36 \\
\text { first weeks }\end{array}$} & \multicolumn{2}{|c|}{$\begin{array}{c}\text { Weights * after calving, } \\
\text { kilogrammes }\end{array}$} & \multicolumn{2}{|c|}{$\begin{array}{l}\text { Increase in weight, }{ }^{*} \text { kilo- } \\
\text { grammes, from calving } \\
\text { to } 36 \text { weeks thereafter }\end{array}$} \\
\hline & $A$ & $a$ & $A$ & $a$ & $A$ & $a$ \\
\hline $\begin{array}{l}322-323 \\
327-328 \\
403-404 \\
409-410 \\
411-412\end{array}$ & $\begin{array}{l}2,462 \\
3,722 \\
2,740 \\
2,550 \\
2,987\end{array}$ & $\begin{array}{l}2,742 \\
3,373 \\
2,613 \\
2,902 \\
2,765\end{array}$ & $\begin{array}{l}450 \\
530 \\
410 \\
510 \\
490\end{array}$ & $\begin{array}{l}370 \\
410 \\
375 \\
410 \\
415\end{array}$ & $\begin{array}{l}30 \\
10 \\
70 \\
65 \\
40\end{array}$ & $\begin{array}{r}55 \\
5 \\
35 \\
20 \\
50\end{array}$ \\
\hline Total & 14,461 & 14,395 & $\ldots$ & $\ldots$ & 215 & 165 \\
\hline
\end{tabular}

* All weight figures are preliminary and uncertain (see text). This is especially the case with the increases in weight during lactation, which have been inserted in the table merely to show the general trend of the individual cows.

results. (N.B.-The weights are preliminary and may be adjusted later. This is due to the circumstance that "true" weights are found by a graphically made fitting of the actually observed weights and this fitting cannot be undertaken until some time has elapsed. Therefore the uncertainty refers especially to the increase in weight 
during lactation.) From the table it will first be seen that the average production (milk yield as well as increase in weight) is practically equal for $A$ - and for $a$-animals. There are further marked differences between the milk yield of the different pairs, whereas the differences within the pairs are comparatively much smaller. The mean square of F.C.M. between pair means is 7.5 times the mean square within pairs, which is a further evidence for supporting the idea of a genetically determined ceiling. In three of the pairs, the higher fed animal, the $A$-animal, has actually yielded more fat corrected milk than her low-fed twin sister. In two of the pairs, on the other hand, the converse is the fact. In the pair 409-4Io the 350 kilogrammes higher milk yield of the $a$-animal is, however, compensated by a much higher increase in body weight (I kilogramme of body weight corresponds roughly to Io kilogrammes of F.C.M.), but in the pair $322-323$, the $a$-animal has produced more milk as well as more body weight during lactation. It seems as if the ceiling of this pair lies below what corresponds to the $a$-animals' feed consumption, and that consequently the $A$-animal of this pair has been heavily overfed. This overfeeding has then disturbed the general metabolism of the animal in question to such a degree that it was not able to reach its ceiling.

Of course, everything is not explained merely by using the word "ceiling." The "ceiling" concept contains the essentials of some law, and as we believe, a profound law. But we do not know anything of the mechanism underlying this law. In the case of milk yield the site of this regulating mechanism is naturally sought in the milk gland. But it may also in part be situated in the absorption epithelium of the intestine and, more generally, in all organs contributing to metabolism and transport. Now, the metabolising capacity is related to the composition of the feed, some kinds of feed being more easily absorbed and metabolised than others. But in our experiments there are chiefly quantitative differences between the feed of $A$ - and $a$-animals. Thus we do not know if, and how, the level of the ceiling is dependent on qualitative feed differences. In order to be cautious, therefore, the definition of the ceiling concept should be adjusted by saying: Corresponding to each genotype and to each kind of feed composition there exists a ceiling characterised thus : (I) An increase in the amount of feed above the ceiling level is not followed by an increase in the production; but may be followed by a decrease if the increase in feed is very strong. (2) A decrease in the amount of feed below the ceiling level is followed by a decrease in the production. As, however, the feed given to the animals in well-kept herds-such as the Animal Breeding Institute's twin herd-is usually of an adequate composition, it does not seem very likely that a qualitative change in this composition will be able to increase appreciably the production of a cow, which has reached its ceiling with the earlier feed composition. 
In the definition of the ceiling concept modified above, we spoke of the ceiling as forming an upper boundary of the "production" of a cow. But a cow's "production" is composed of several factors among which the most important are milk yield and growth. How these different parts will be proportioned under the ceiling is probably impossible to predict, but here also there are genetically-determined forces in action.

As will be seen, the definition of the ceiling concept at which we have so far arrived is not a very precise one. It is probable that, with more knowledge, it will be adjusted several times, thereby gaining in precision. But it seems to us that it is a simple and useful descriptive word, which, as said above, contains an important genetical truth.

\section{THE COMPONENTS OF THE VARIANCE}

As mentioned above, experiments with identical twins make it possible to divide the variance into its three natural parts, viz. that due to heredity, that due to environment, and that due to non-linear interactions between heredity and environment. When, however, comparing two different experiments, such as our experiments IV and VI ( 1 and 2 in the description, p. 12), it is also of great interest not only to know the variances but also the mean squares. Table 4 contains such a comparison for three different measurements and for the live weights at 6 and 24 months of age. When looking at this table it must be remembered that both these experiments were, during growth, planned according to interpretation 2 of the equality principle. The difference between the feed amount of $A$ - and $a$ animals was, however, different in the two experiments ; in experiment IV the feeding was 33 per cent. above and below normal, but in experiment VI it was only 25 per cent. above and below normal. It is therefore natural to find that the mean squares for environment are much larger in the case of experiment IV than in the case of experiment VI. Concerning the mean squares due to heredity, they are as a rule somewhat larger in experiment VI than in experiment IV. In samples containing so relatively few pairs as in these experiments, one cannot expect that the representativeness of the breed will be equally well expressed in each sample. It is therefore not astounding that one of the samples, VI, shows a somewhat greater diversity than another sample, IV.

In an analysis such as that made here it is impossible to eliminate error variation from interaction variation. That there is nevertheless reason to suppose that non-linear interactions sometimes really do occur may be shown in an indirect way. We have 8 pairs of identical twins in which, during growth, all animals have been normally fed without any feeding differences between the two members of the different pairs. Thus the average variation between two twin sisters here constitutes a good estimate of variation due to error. The live 
5

造

2

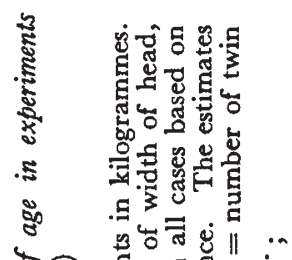

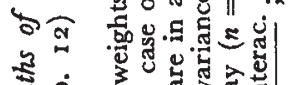

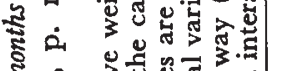

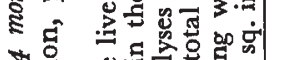

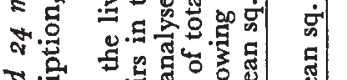

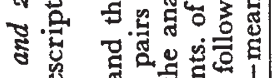

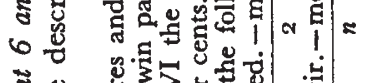

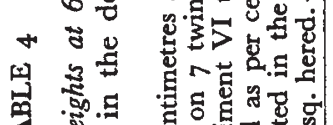

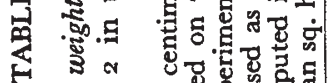

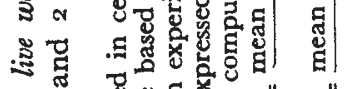

Б -

उ

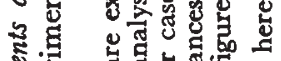

है

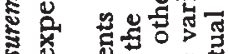

氝

(

\&

s $\quad$ ₹.

\& ख

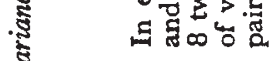

\begin{tabular}{|c|c|c|c|c|c|}
\hline \multirow{4}{*}{ 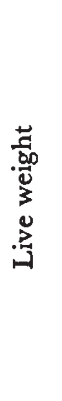 } & \multirow{2}{*}{ 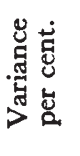 } & 5 & i g & & $=$ 串 \\
\hline & & $\geq$ & $\infty \quad \infty$ & & $\infty \underset{\infty}{\infty}$ \\
\hline & \multirow{2}{*}{ 㱐 } & 5 & 总 学 & & 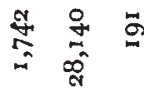 \\
\hline & & $\geq$ & 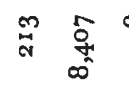 & $\stackrel{\text { g }}{\infty}$ & 怘 \\
\hline \multirow{4}{*}{ 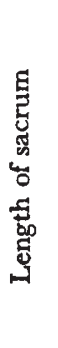 } & \multirow{2}{*}{ 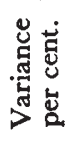 } & 5 & 品 : & สี & $\therefore$ in 8 \\
\hline & & $z$ & is 8 & n & $=\infty-$ \\
\hline & \multirow{2}{*}{ 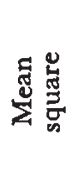 } & 5 & $\dot{\dot{g}}$ & $\stackrel{\varphi}{i}$ & 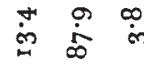 \\
\hline & & $\geq$ & 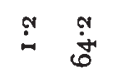 & & 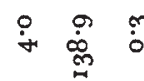 \\
\hline \multirow{4}{*}{ 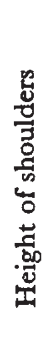 } & \multirow{2}{*}{ 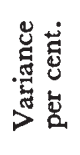 } & 5 & 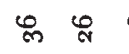 & $\stackrel{\infty}{\infty}$ & $\notin \infty=$ \\
\hline & & $\geq$ & యั & $n$ & $F=\infty$ \\
\hline & \multirow{2}{*}{ 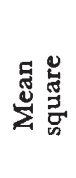 } & 5 & $\overrightarrow{\dot{s}}$ & $\dot{\sigma}$ & 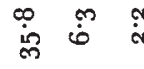 \\
\hline & & $\geq$ & $\stackrel{m}{\dot{\phi}}$ & $\stackrel{n}{\sim}$ & $\begin{array}{l}\dot{*} \\
\dot{\phi}\end{array}$ \\
\hline \multirow{4}{*}{ 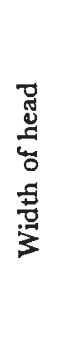 } & \multirow{2}{*}{ 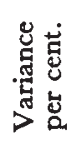 } & 5 & ఉ $\quad \vdots$ & $\mathscr{1}$ & $\infty r=$ \\
\hline & & $\geq$ & $\stackrel{\sigma}{\infty} \tilde{0}$ & $\approx$ & in 融? \\
\hline & \multirow{2}{*}{ 㺼 } & 5 & 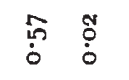 & $\stackrel{\leftrightarrow}{\circ}$ & $\begin{array}{c}\mathscr{O} \\
\text { aे }\end{array}$ \\
\hline & & $\geq$ & $\stackrel{\circ}{\ddot{i}} \stackrel{n}{i}$ & $\stackrel{\infty}{\breve{0}}$ & 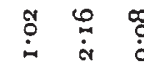 \\
\hline & \multicolumn{2}{|l|}{ 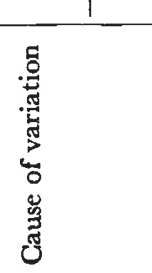 } & 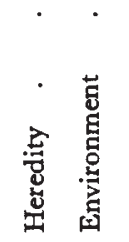 & 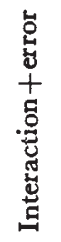 & 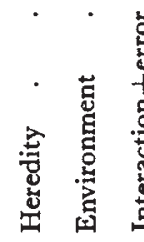 \\
\hline & \multicolumn{2}{|l|}{ 突尊 } & & \\
\hline
\end{tabular}

B 2 
weights have been checked for all 8 pairs, only 5 of them, however, having been measured. The mean squares are found in table 5 .

TABLE 5

Mean squares due to error. Figures from twin pairs within which no feeding differences occurred. Analysis of weights is based on 8 pairs, of measurements on 5 pairs

\begin{tabular}{|c|c|c|c|c|}
\hline Age & Width of head & Height of shoulders & Length of sacrum & Live weight \\
\hline $\begin{array}{c}6 \text { months } \\
24,\end{array}$ & 0.05 & 0.72 & $1 \cdot 05$ & $54 \cdot 5$ \\
& 0.25 & $1 \cdot 27$ & $1 \cdot 22$ & $65 \cdot 0$ \\
\hline
\end{tabular}

These mean squares are, of course, only more or less correct estimates of the true error mean squares, but in some cases at least they are of a decidedly lower order of magnitude than the combined interactionerror mean squares in table 4 .

As pointed out above, the difference in feeding intensity between $A$ - and $a$-animals is greater in experiment IV than in experiment VI. If we adhere to the ceiling concept and suppose tha all $A$-animals in both experiments have reached their ceilings, the feeding differences between the two experiments may also be expressed by saying that the undernourishment of the $a$-animals is less pronounced in VI than in IV. In this connection it is interesting to note that different measurements have reacted differently in the two experiments. Thus, in the case of the width of the head, there is practically no influence of environmental differences between $A$ - and $a$-animals in experiment VI, but a rather marked one in experiment IV (table 4). Now the feeding difference in VI was 25 per cent. above and below normal, and 33 per cent. above and below normal in IV. It may seem that the 8 per cent. higher severity of undernourishment in IV ought not to have had such a profound effect. The explanation would appear to be that there exists a critical level ; if the undernourishment remains below this level there will be no effect, but if the undernourishment is more severe the effect will show. In fact, this level is only a new aspect of the "ceiling." The interesting point, however, is that there seems to be a kind of a gradient which apparently runs from the head backwards ; the ceiling is reached with quite a low feed in the case of the width of head, with a somewhat higher feed in the case of the height of shoulders, and with a still higher feed in the case of length of sacrum. Finally, it seems probable that the feeding intensity may be such that whereas the ceiling of the live weight is not attained, the "ceiling" of all body measurements are reached.

Analyses of similar kinds may be made also for milk yield. It is, though, somewhat too early to analyse our experiment VI. For experiment IV (experiment I in description, p. I2) we have, however, 2 lactations for 6 pairs. In each of these lactations the analysis 
comprises 9 periods of 28 days each. It may be remembered that in this experiment all animals after first calving have been normally fed with regard to individual weights and yields. As shown earlier in a preliminary paper (Bonnier, I $946 b$ ), the effect has been that the $a$-animals, which were decidedly undernourished prior to calving, have, after calving, used relatively more feed for their residual

TABLE 6

Analysis of variance in milk-calories (unit $=$ rooo calories). Figures based on 6 twin pairs from experiment IV (experiment $\mathrm{I}$ in description, p. 12)

For computations of estimates of variance see table 4

\begin{tabular}{|l|c|c|c|c|}
\hline \multirow{2}{*}{ Cause of variation } & \multicolumn{2}{|c|}{ Mean squares } & $\begin{array}{c}\text { Variance in per cent. of } \\
\text { total variance }\end{array}$ \\
\cline { 2 - 5 } & Lactation I & Lactation II & Lactation I & Lactation II \\
\hline Heredity & 180,719 & 741,383 & 39 & 91 \\
Environment. & 176,104 & 112,947 & 12 & 4 \\
Interaction+error . & 70,260 & 20,342 & 49 & 5 \\
\hline
\end{tabular}

TABLE 7

Analysis of variance in total calories from milk and gain in weight from the 5 th to 36 th week of each of the two first lactations. One kilogramme's gain in weight is made equal to 7500 calories (unit $=$ rooo calories). Figures based on 6 twin pairs from experiment IV (experiment $I$ in description, p. 12)

For computation of estimates of variance see table 4. As the mean square for environment in lactation $I$ is smaller than the interaction mean square this would lead to a negative variance of 7 per cent. These have been deducted from the interaction percentage, which, if computed directly, would have given 40 per cent.

\begin{tabular}{|c|c|c|c|c|c|}
\hline \multirow{2}{*}{\multicolumn{2}{|c|}{ Cause of variation }} & \multicolumn{2}{|c|}{ Mean squares } & \multicolumn{2}{|c|}{$\begin{array}{l}\text { Variance in per cent. of } \\
\text { total variance }\end{array}$} \\
\hline & & Lactation I & Lactation II & Lactation I & Lactation II \\
\hline Heredity & . & 231,901 & 834,568 & 67 & 84 \\
\hline Environment . & . & $6 \mathrm{r}$ & 123,180 & $\ldots$ & 2 \\
\hline Interaction + error & . & $\mathrm{I}, 408$ & 62,586 & 33 & 14 \\
\hline
\end{tabular}

growing power. Therefore the $a$-animals have yielded less milk than their $A$-sisters during first lactation. But, as the $a$-animals have used more feed for growth than the $A$-animals, the average weight difference between $A$ and $a$ is less during the second lactation than during the first and, consequently, the difference in milk yield between $A$ and $a$ is also less during second lactation than during first. In table 6 an 
analysis is made of the calories within the milk, and in conformity with what has just been said, the hereditary part of the variance increases greatly from first to second lactation. If the increase in live weight is added by evaluating an increase of I kilogramme as equalling 7.500 calories, the result will be that shown in table 7 , i.e. the average total production of calories is approximately equal for $A$ - and $a$-animals, and practically no influence of environment upon variance is found. In a special analysis (on fat yield) we have found that error cannot probably contribute more than 2 per cent. of the total variance; hence during lactation there is a marked non-linear interaction between heredity and environment.

\section{SUMMARY}

I. This paper begins with a review of earlier cases and studies of identical cattle twins.

2. The high efficiency of experiments with identical twins is stressed.

3. Some important questions with regard to the design of twin experiments are discussed.

4. The "ceiling" concept of a genotype's yielding capacity is discussed and examples given supporting the assumption that this concept covers a genetical truth.

5. The variance in different experiments is divided into its components, viz. that due to heredity, to environment and to nonlinear interactions between heredity and environment.

\section{REFERENCES}

BONNIER, G. I930

Institutet för husdjursförädling, meddelande 3, 27-32.

BONNIER, G. I93I.

Institutet för husdjursförädling, meddelande 4, 20-24.

BONNIER, G. I 932 .

Institutet för husdjursförädling, meddelande 5, 14-16.

BONNIER, G. I946a.

Studies on monozygous cattle twins. II. Frequency of monozygous cattle twins.

Acta Agr. Suec. 1, I47-151.

BONNIER, G. I $946 b$.

On the interactions of heredity and environment in growth and milk-yield, as elucidated by experiments with monozygous cattle twins.

K. Lantbruksakad. tidskr. 85, 3, 22 I-240.

BONNIER, G., AND BÄCKSTRÖM, K. I935.

Några försök med överutfodring av nötkreatur.

Lantbruksakad. handl. och tidskr. I-23.

BONNIER, G., AND HANSSON, A. 1946.

Studies on monozygous cattle twins. V. The effect of different plans of nutrition on growth and body development of dairy heifers.

Acta Agr. Suec. I, I 7 I-205. 

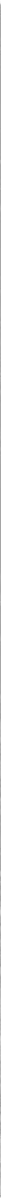

(a)
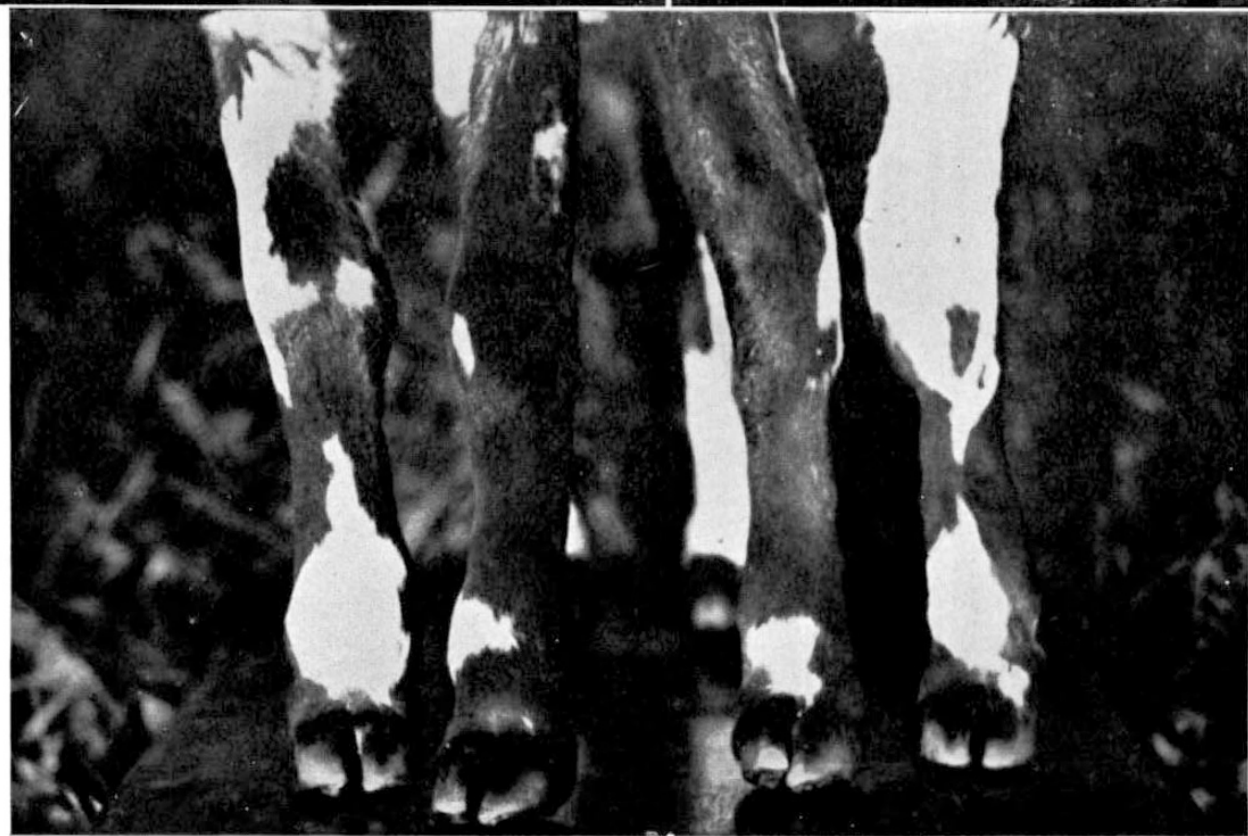

(b)

Photographs of a Siamese pair : (a) left head; $(b)$ right head ; $(c)$ four forelegs. Note dissimilarity of markings on the two heads and mirror imaging of markings on the legs. 
BONNIER, G., HANSSON, A., AND DÜRING, T. 1946.

The efficiency of the Twin Method.

K. Lantbruksakad. tidskr. 85, 455-467.

COoK, R. 1940.

Are they identical ?

7. Hered. 3I, 454 .

DAIRY DIVISION. 1940.

Identical Twin Heifers.

7. Agric., New Zealand, p. 113 .

FISHER, R. A. 1935.

The design of experiments.

Edinburgh : Oliver and Boyd Ltd.

GOWEN, JOHN W. 1922.

Identical twins in cattle.

Biol. Bull. 42, I-6.

HAAK, D. 1942.

Untersuchungen an eineiigen und zweieiigen Rinderzwillingen u.s.w.

Züchtungskunde $17,326-330$.

HAAK, D. 1943.

Untersuchungen an eineiigen und zweieiigen Rinderzwillingen u.s.w.

Z.f. Tierzüchtung $u$. Züchtungsbiol. 54, 27-77.

HAYDEN, C. C. 1922.

A case of twinning in dairy cattle.

7. Hered. $13,22-24$.

HUTT, F. B. 1930.

Bovine quadruplets.

7. Hered. 21, 339-348.

KELLER, K. 1933 .

Ueber die elementaren Grundlagen der Zwillingsforschung an der Haussäugetieren und über ihren derzeitigen Stand beim Rind.

Züchtungskunde 8, 21 3-228.

KELLER, K., UND TANDLER, J. 1916.

Ueber das Verhalten der Eihäute bei der Zwillingsträchtigkeit des Rindes.

Wiener Tierärztl. Wochenschr. 3, 513-526.

KRONACHER, C. 1930 .

Die Zwillingsforschung beim Rind, ihre Bedeutung Grundlagen und Wege.

Deutsch. Landwirtsch. Tierzucht., pp. 851-853, 872-874.

KRONACHER, C. 1932.

Zwillingsforschung beim Rind.

Z.f. Ziichtung., B. 25, 327-414.

KRONACHER, C. 1936.

Eineiige Drillinge beim Rind.

Z.f. Züchtung., B. 36, 267-28o.

KRONACHER, C., UND HOGREVE, F. 1936.

Röntgenologische Skelettstudien an Dahlemer Rinder-Drillingen und- Zwillingen.

Z.f. Züchtung., B. 36, 281-294.

KRONACHER, C., UND SANDERS, D. 1936.

Neue Ergebnisse der Zwillingsforschung beim Rind.

Z.f. Züchtung., B. $34, \mathrm{I}-83, \mathrm{1} 33-220$. 
LILLIE, FRANK R. 1916.

The theory of the Free-martin.

Science $43,611-613$.

LILLIE, FRANK R. 1917 .

The Free-martin. A study of the action of sex hormones in the fotal life of cattle. 7. Exp. Zool. 23, 371-451.

LILLIE, FRANK R. 1923.

Supplementary notes on twins in cattle.

Biol. Bull. 44, 47-78.

" LIST." 1947.

List of experiments with identical cattle twins conducted at the Animal Breeding Institute, Wiad, Eldtomta, Sweden, 1947.

LUSH, JAY L. I 1924 .

Twinning in Brahma Cattle.

7. Hered. $15,25-27$.

LUSH, JAY L. I I929.

Twins in Jersey cattle.

7. Hered. $20,5 \mathrm{II}-5 \mathrm{I} 3$.

LUSH, JAY L. 1935. Progeny test and individual performance as indicators of an animal's breeding value.

7. Dairy Sci. 18, 1-19.

LUSH, JAY L. 1936.

Genetic aspects of the Danish system of progeny-testing swine.

Iowa State Coll. Agr. Res. Bull., p. 204.

LUSH, JAY L. 1940.

Intra-sire correlations or regressions of offspring on dam as a method of estimating heritability of characteristics.

Proc. Amer. Soc. Anim. Prod., pp. 293-301.

LUSH, JAY L., AND STRAUS, F. S. 1942.

The heritability of butterfat production in dairy cattle.

7. Dairy Sci. 25, 975-982.

NEW ZEALAND DAIRY BOARD, 1946.

Twenty-second annual report, p. 71 .

OWEN, R. D. 1945.

Immunogenetic consequences of vascular anastomoses between bovine twins.

Science 102, 400-401.

PETERS. I 1939 .

Was lehrt die Lebensgeschichte der beiden eineiigen Zwillingskühe Bagage und Banane in Podangen/Ostpreussen.

Deutsch. Landwirtsch. Tierzücht., pp. 262-264.

SANDERS, D. 1935.

Untersuchungen an zweieiigen Rinderzwillingen hinsichtlich der Ähnlichkeit morphologischer, physiologischer und psychologischer Merkmale.

Z.f. Züchtung., B. 32, 223-268.

SCHMIDT, J., UND KLIESCH, J. 1938.

Untersuchungen und Beobachtungen an eineiigen Rinderzwillingen.

Kühn-Archiv. 49, 65-78. 
WRIGHT, s. 1920 .

The relative importance of heredity and environment in determining the piebald pattern of guinea-pigs.

P.N.A.S. 6, 320-332.

WRIGHT, s. I92I $a$.

Correlation and causation.

7. Agric. Res. 20, 557-585.

WRIGHT, s. I $192 \mathrm{I} b$.

Systems of mating.

Genetics 6, I I I-I 78 . 